\title{
A SEPARAÇÃO DOS TORRŌES DE TERRA ROXA DO CAFÉ, PELO MAGNETISMO
}

\author{
ANDRE Toski.Lo \\ Engenheiro agrônomo, Secção de Café, Instituto Agronûmico de Campinas
}

\section{1 - INTRODUÇÃO}

Nas zonas de terra roxa, o problema da separação dos torrões de café tem chamado a atenção dos estudiosos do assunto, pois a que é comumente realizada nos "catadores de pedras" não é feita com a eficiência desejada.

A separação através do "catador de pedras" não pode ser eficiente por se basear ùnicamente na diferença de resistência à pressão exercida por uma coluna de vento vertical ou horizontal sôbre o torrão e sôbre o café. $\hat{\mathrm{E}}$ sabido que a impulsão que sofre um torrão mergulhado numa dada corrente de ar depende de dois fatôres : pêso específico do torrão e diâmetro dêste (admitido que seja de forma esférica). Dêste modo, se as diferenças de pêso específico entre os corpos não forem suficientemente grandes, a separação pelo ar, sem uma prévia classificação por tamanhos, não poderá ser eficiente (fig. 1).

Por êstes motivos, os meios atualmente postos em prática para a sepdração dos torrões têm sido os seguintes: ciente ;

a) separação por intermédio do "lavador", que, aliás, é bastante efi-

b) separação por intermédio do "seletor", o qual divide o café da roça em lotes mais ou menos uniformes em relação às dimensões dos grãos e, em seguida, os submete à corrente de ar. Este processo é eficiente para os frutos cereja e bóia, sendo que para o coquinho (1) e casquinha $\left(^{(2)}\right.$ a eficiência é bem menor.

Nas zonas de terra roxa produtoras de café e principalmente nas zonas novas, como média Sorocabana e norte do Paraná, onde o café, na grande maioria dos casos, é derriçado no chão e onde não existem "lavadores" nem "seletores", a separação dos torrões ùnicamente feita pelo "catador de pedras" não satisfaz, o que acarreta depreciação do tipo e da bebida.

Os torrões de terra roxa que não foram prèviamente separados vão com o café em casca para o descascador e aí quando êste é esbrugado se desfazem, tingindo o café beneficiado. Aquêles que conseguem sair do descascador acompanham o café beneficiado até as peneiras e são submetidos

(1) Café coquinho é o fruto sêco do café, produzido geralmente nos ramos ponteiros e porisso de tamanho pequeno.

(2) Café casquinha é o café despolpado por diversas causas, na lavoura, e que vem nesse estado iuntamente com o café protegido pela casca. 
à corrente de ar juntamente com os grãos. Esta efetua uma separação eficiente dos torrões em relação aos grãos de café maiores (peneiras 15,16, etc.), porém ineficiente para os grãos pequenos (peneiras 14,13,12, moquinha e chatinho), além de sobrecarregar as escolhas com êsse detrito.

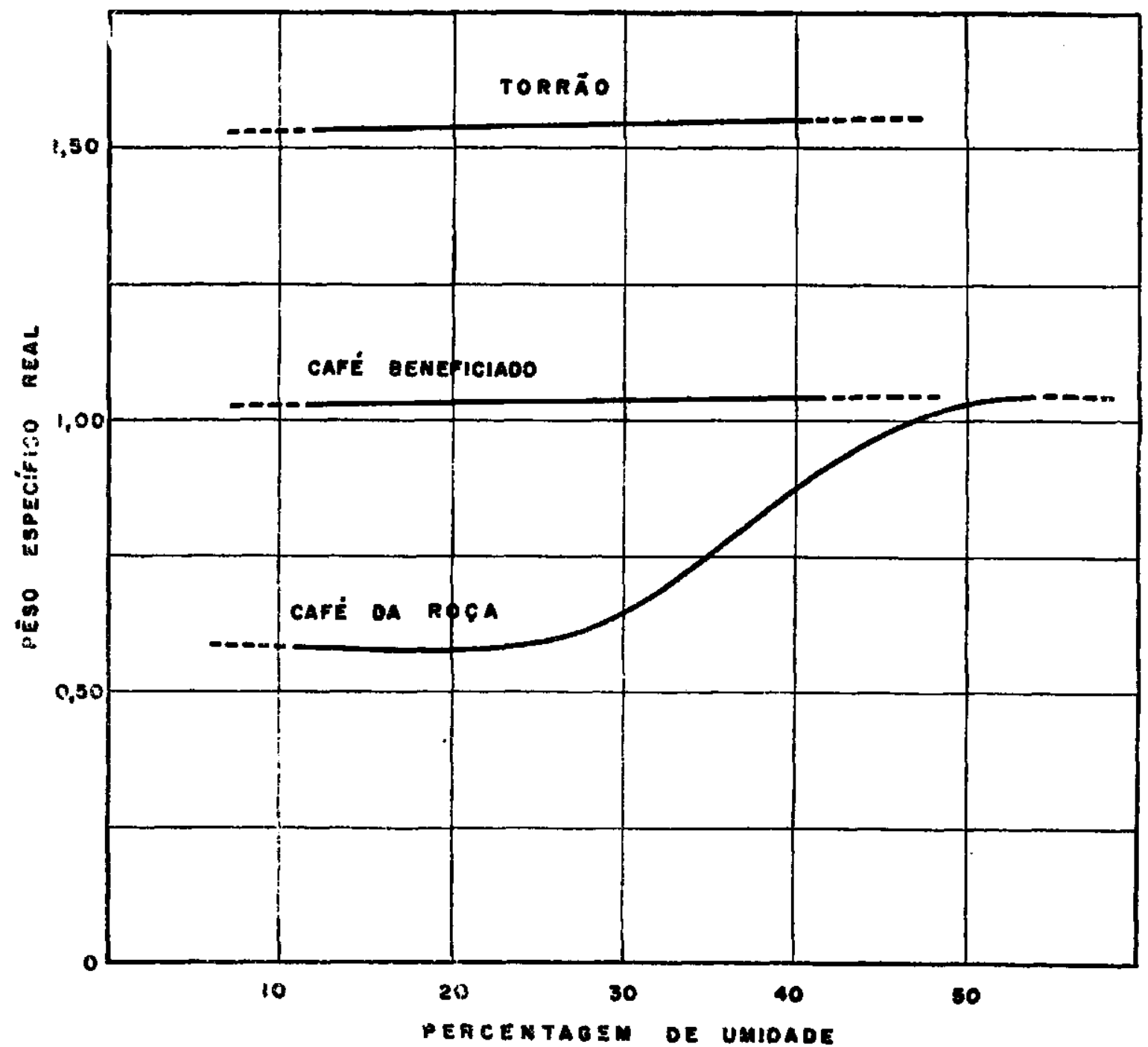

FIgURA 1.-Curvas de variação do pêso especifico real do café de roça, café beneficiado e do torrão de terra em fungrono da umiclade.

O café "tinjido" pela terra roxa é bastante depreciado nos mercados consumidores e os grãos que não são convenientemente separados dos torrões são também muito prejudicados na classificação de tipos. Basta lembrar que, na tabela correspondente, se tem :

1 pedra grande é equivalente a 5 defeitos

1 pedra regular é equivalente a 2 defeitos

1 pedra pequena é equivalente a 1 defeito

Nestas condições, o advento de qualquer processo ou máquina eficiente para a separação dos torrōes de terra roxa será de grande importância, principalmente para as propriedades agrícolas situadas nas zonas indicadas e que não possuam lavador ou seletor ou que, possuindo-os, desejem realizar 
uma catação no café beneficiado ; é de interêsse também para os compradores de café que efetuam o rebeneficiamento.

$\widehat{E}$ conveniente que se faça a separação dos torrões antes de o café passar pelo descascador ; porém, quando isto não seja possível, é desejável que se faça a separação dos torrões do café beneficiado. $\hat{E}$ claro que seria ótimo se se procedesse à separação antes e depois de o café ser descascado.

$O$ presente trabalho tem por objetivo o estudo de um tipo de máquina que permita a separação dos torrões antes de o café ser beneficiado, ou em qualquer fase do seu preparo.

\section{2 - SEPARAÇÃO MAGNÉTICA DOS TORRÕES}

É sabido que a terra roxa contém apreciável quantidade de óxido de ferro, principalmente na forma de magnetita $\mathrm{Fe}_{3} \mathrm{O}_{4}$. Segundo dados da Secção de Agrogeologia do Instituto Agronômico, em alguns casos a quantidade de magnetita dosada foi da ordem de $8 \%$. A quantidade de magnetita nos torrões é pequena, resultando disso que, apesar do ferromagnetismo (susceptibilidade magnética) dêsse material, os torrões se tornam pouco sensíveis ao campo magnético. Nestas condições a separação só é pràticamente realizável, com eficiência, por intermédio de ímãs de alto poder magnético (de grande intensidade de campo magnético).

Existem, entre outros, dois processos práticos e econômicamente realizáveis, a saber : por intermédio de eletroímãs ou por intermédio de ímãs permanentes de alto poder.

\section{1 - APLICAÇÃO DOS ELETROİMÃS}

Os eletroímãs são muito empregados na concentração de minérios, e os mais usados são os chamados separadores de tambor (1). Êstes funcionam do seguinte modo : dentro de um tambor rotativo (fig. 2), existe um ele-

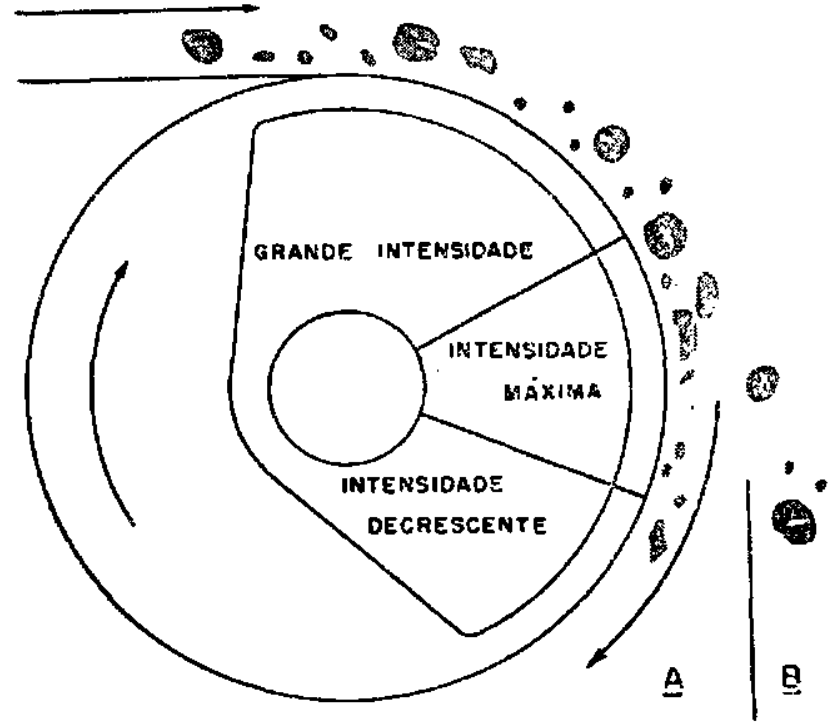

Figura 2.--Esquema de um separador de tambor metálico eletromagnético empregado na concentração de minérios. $A$ - Material magnético; $B$ - material não magnético. 
troímã fixo, dividido em três setores, com campos eletromagnéticos de intensidades diferentes. $\mathrm{O}$ material magnético adere à superfície do tambor e é arrastado com êle até passar a zona magnetizada e depois cai livremente, ao passo que o material não magnético é lançado fora pela ação da fôrça centrífuga.

Para se ter idéia da produção de um separador de tambor, damos a relação que se segue (5).

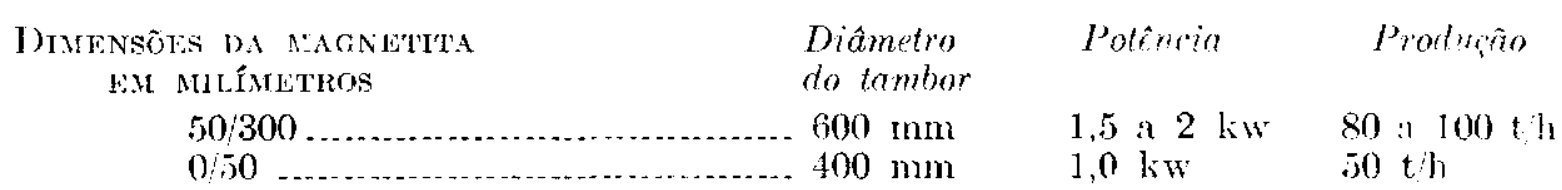

Os inconvenientes da aplicação dos eletroímãs na separação de torrões consistem principalmente nos seguintes pontos: a) instalação cara; b) necessidade de uma assistência constante; c) disponibilidade de energia elétrica. Em grande parte das fazendas de café das zonas novas de terra roxá, a obtenção dos dois últimos itens é difícil.

Os eletroímãs do tipo de tambor não deram resultados satisfatórios na separação dos torrões, segundo informações sblidas, e isto principalmente devido à forma do entreferro.

\section{2-CATADOR "DR. ISAY"}

O separador de torrões denominado "Catador Dr. Isay" é do tipo de tambor, porém o campo magnético é produzido por intermédio de ímãs permanentes rotativos. O Dr. Rudolf Isay, inventor do referido catador, especializara-se em questões relativas à mineração. Lavrador de café em Rolândia, Estado do Paraná, há 15 anos teve a atenção voltada para o problema da separação dos torrões de terra roxa. IIá pouco tempo iniciou a fabricação e venda do seu catador, o qual tem sido regularmente difundido na zona cafeeira de Londrina.

O "Catador Dr. Isay" consta, em síntese, do seguinte (fig. 3,4 e 5 ) :

1) bica de jôgo para a alimentação regular do café no rôlo magnético (fig. $3-A$ );

2) plano inclinado construído de material não magnético (latão) regulável, cuja finalidade é conduzir o café, uniformemente distribuído, ao ponto ótimo do rôlo magnético (figr. $3-B$ ) ;

3) rôlo magnético rotativo (fig. 3-C), cujos detalhes construtivos estão inclicados na figura $3-F$, e que são:

a) entreferro, construído de material de boa permeabilidade magnética (fig. 3-F, a) ;

b) ímã permanente, construído de material de alto poder magnetizante, como, por exemplo, alnico (fig. $3-F, b$ );

c) anel isolante construído de latão (fïg. 3-F, c) ;

d) eixo construído de material não magnético, latão ou bronze (fïg. $3-F, d)$; 


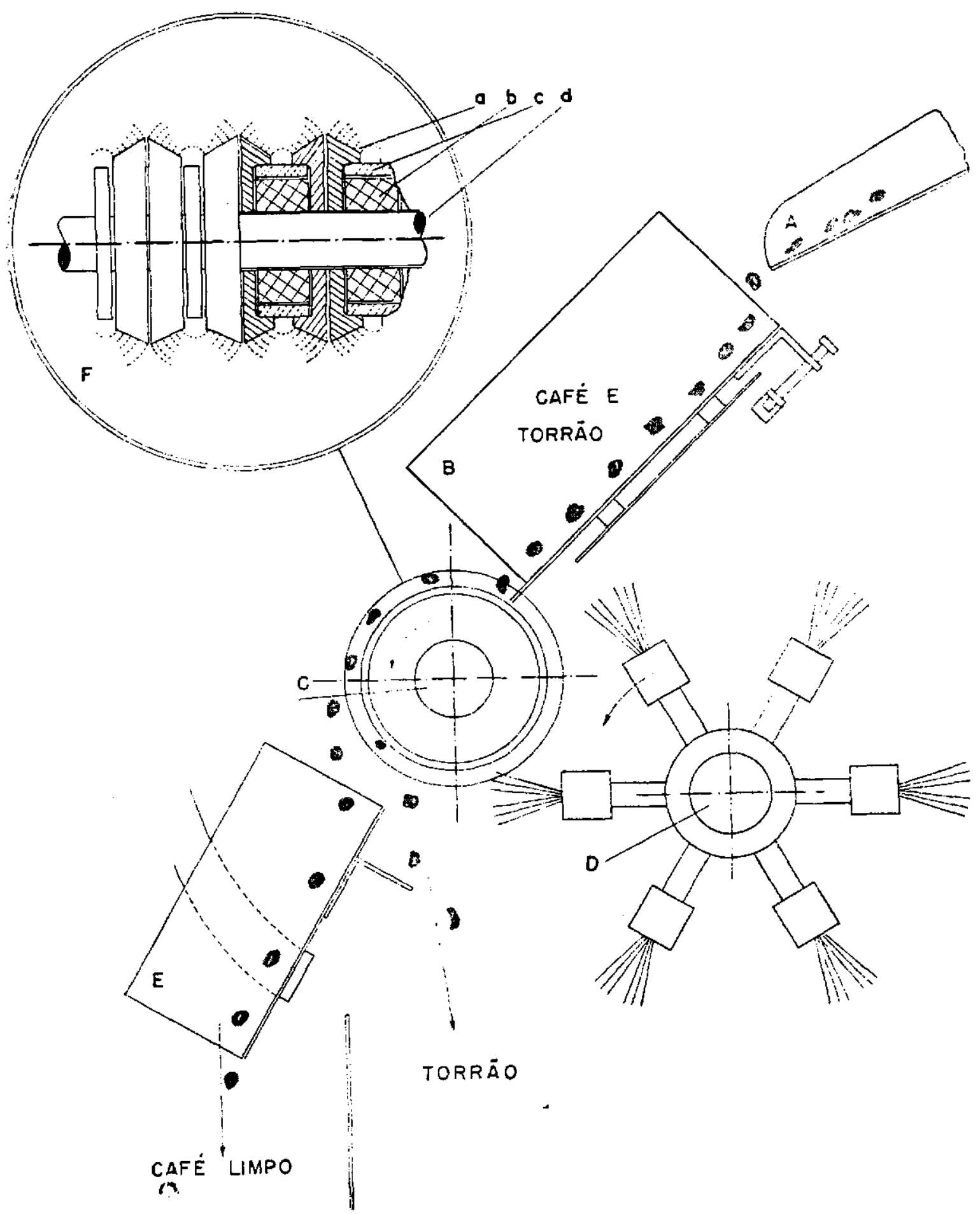

Figria 3.--Esquema do funcionamento do "Catador Dr. Isay". $A$ - Biea de jôgo; $B-$ plano inclinado; $C$-rôlo magnético; $D$-escôvas giratórias; $E$ - plano inclinado; $F$-corte do rôlo magnético; $a$-entreferro; $b$-ímã permanente; $c$ - anel isolante; $d$ - eixo.

e) escôvas giratórias, cuja finalidade é retirar as partículas de terra roxa que foram atraídas pelo rôlo magnético (fig. $3-D$ ) ;

f) plano inclinado, também regulável, cuja finalidade é receber os grãos não magnetizados que foram repelidos pela ação da fôrça centrífuga (fig. 3-E). 

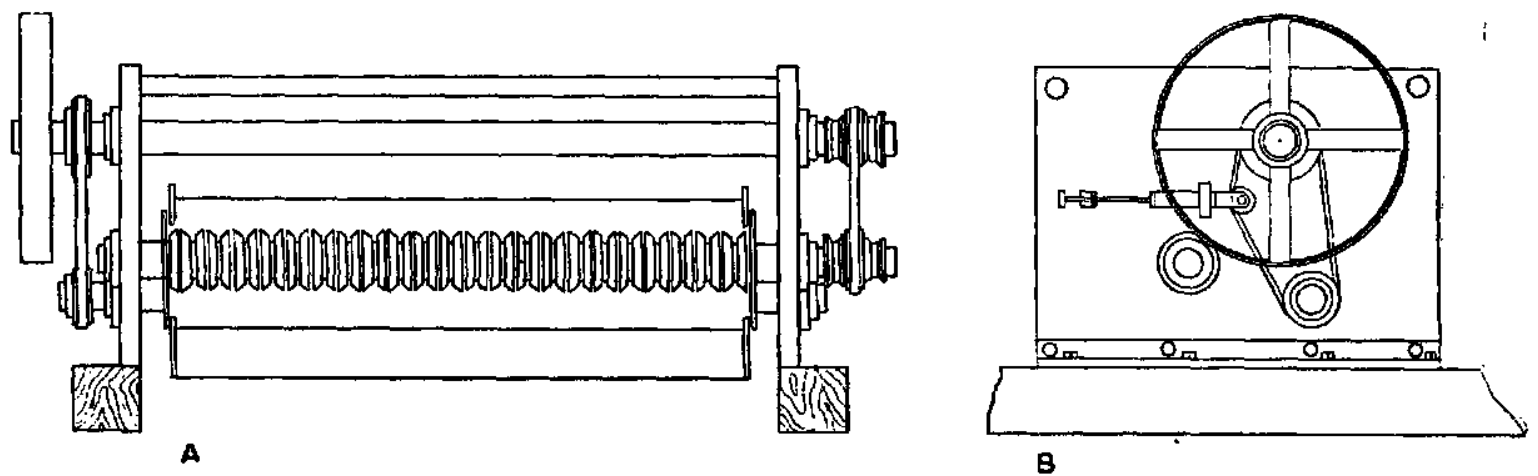

Figura 4.-Catador Dr. Isay; $A$-vista de frente; $B$ - vista lateral.

\section{3 - ENSAIOS REALIZADOS}

A fim de se ter uma idéia da eficiência do "Catador Dr. Isay", levamos a efeito alguns ensaios na Secção de Café do Instituto Agronômico, dos quais transcrevemos três fichas com os dados mais interessantes (6):

ENSAIO N..$^{\circ} 23$

DATA : 8 de setembro de 1950

Assunto : Catador Dr. Isay

Local : Máquina de beneficiar café de Reinaldo Massi

Rolândia - Estado do Paraná

Finalidade : Determinação da eficiência do separador de torrões de terra roxa contidos no café beneficiado pelo "Catador Dr. Isay".

Dados oвtridos: Com base na velocidade do motor elétrico que acionava o "Catador Dr. Isay", foram calculadas as seguintes velocidades :

Motor

Bica de jôgo

Rôlo magnético

Escôvas

1680 r.p.m

409 r.p.m

238 r.p.m

400 r.p.m

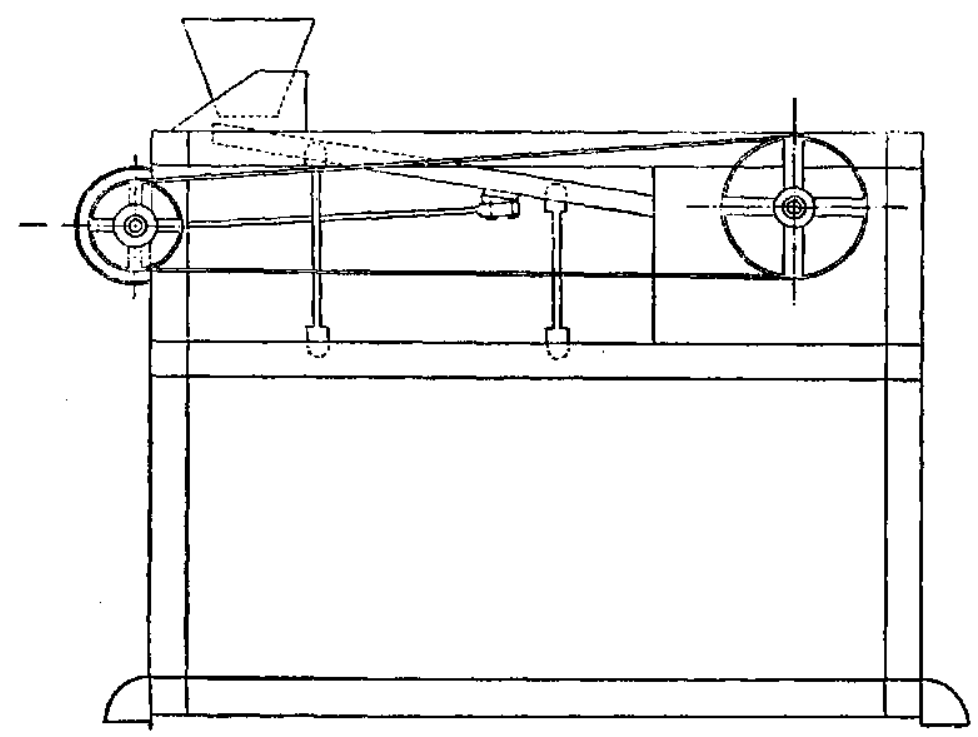

Figura 5.-Catador Dr. Isay. Vista lateral com a bica de jôgo. 
As velocidades periféricas do rôlo magnético (no seu diâmetro médio) e da escôva são, respectivamente : $1 \mathrm{~m} / \mathrm{s}$ e $4,2 \mathrm{~m} / \mathrm{s}$.

Após uma hora de trabalho em regime de produção de 40 sacos de café beneficiado por hora, foram retiradas algumas amostras, e o resultado médio obtido foi o seguinte :

Amostra de 300 gramas de café não catado : 43 torrões.

Amostra de 300 gramas, após a passagem pelo "Catador Dr. Isay" : 5 torrões.

Amostra dos torrões : $0 \%$ de café.

ENSAIO N.॰ 24 :

DATA : 9 de setembro de 1950

Assunto : Catador Dr. Isay

Local: Fazenda Santa Isabel

Propriedade do Dr. Rudolf Isay

Município de Rolândia - Estado do Paraná.

Finalidade : Determinação da eficiência da separação dos torrões de terra roxa, contidos em café em cốco, pelo "Catador Dr. Isay".

DAdos oBtidDos : O café em côco, antes de passar pelo "Catador Dr. Isay", foi separado dos torrões maiores, pelo emprêgo de um catador de pedras. O "Catador Dr. Isay" trabalhou durante meia hora em regime de rotação do rôlo magnético de 180 r.p.m., aproximadamente, e, com algumas amostras, foram obtidos os seguintes dados médios :

Amostra de 300 gramas de café não catado : 5 torróes. torrão.

Amostra de 300 gramas, após a passagem pelo "Catador Dr. Isay" : nenhum

Amostra dos torroes: $0 \%$ de café.

ENSAIO N. ${ }^{\circ} 25$ :

DATA : 10 de setembro de 1950

Assunto : Catador Dr. Isay

LocAL: Fazenda Santa Isabel

Propriedade do Dr. Rudolf Isay

Município de Rolândia - Estado do Paraná

Finalidade : Determinação da eficiência da separação dos torrões de terra roxa, contidos no café da roça, pelo "Catador Dr. Isay".

Dados obtidos : O café da roça utilizado para êste ensaio, dada a época da colheita, já estava, na sua quase totalidade, em adiantado grau de seca.

Foi primeiramente passado num catador de pedras e depois pelo "Catador Dr. Isay". Após uma hora de funcionamento em regime de rotação do rólo magnético de 150 r.p.m., foram retiradas algumas amostras, e os resultados médios obtidos foram os seguintes:

Amostra de 300 gramas de café não catado: 66 torrões.

Amostra de 300 gramas, após a passagem pelo "Catador Dr. Isay" : 2 torrões.

\section{1 - CAPACIDADE DE PRODUÇÃO}

Não tendo sido possível obter com exatidão, nos ensaios 23, 24 e 25, a capacidade de produção da máquina em estudo, usamos as informações que nos foram fornecidas pelo Dr. Rudolf Isay e pelo sr. Reinaldo Massi.

Os dados fornecidos pelo Dr. Isay, retirados da sua escrita contábil, demonstram que num total de 20 horas de trabalho, relativo aos dias 5, 6 
e 7 de setembro de 1950, foram passados cêrca de 685 sacos de 110 litros de café da roça, ou sejam 75.350 litros, o que corresponde a uma produção de $\frac{75350}{20}=3767,5$ litros por hora, ou, ainda, 68 alqueires por hora.

Os dados fornecidos pelo sr. Reinaldo Massi demonstram que, trabalhando com café beneficiado, a produção do "Catador Dr. Isay" é aproximadamente de 40 sacos por hora.

\subsection{7- CUSTO DO TRABALHO}

O preço de venda do "Catador Dr. Isay" é de Cr\$25.000,00. Admitindo-se que, instalado com elevador, motor elétrico, etc., fique em Cr\$ ... $35.000,00$, e, também, que exige duas pessoas para o seu funcionamento (serviço de carga e descarga), podemos dar uma idéia do custo do trabalho de catação, por saco, da seguinte forma:

a) Amortização - Admite-se que a duração total do aparelho seja de 15 mil horas de trabalho, e que o seu trabalho anual seja de 3.000 horas, o que dá um período útil de vida de 5 anos. A amortização horária do capital de $\mathrm{Cr} \$ 35.000,00$, a juros de $6 \%$ ao ano, seria da ordem de $\operatorname{Cr} \$ 3,00$.

b) Pessoal - Admitindo duas pessoas $a^{7} \mathrm{Cr} \$ 3,00$, por hora, cada uma, se têm : $\operatorname{Cr} \$ 6,00$.

c) Energia consumida e assistência - Admite-se que um motor de 3 HP pode tocar a instalação e, nestas condições, pode-se calcular um total de Cr\$ 3,00 por hora para a energia elétrica consumida e assistência mecânica eventual.

Nestas condiçóes, o custo total da hora de trabalho será da ordem de :

Cr\$3,00

Cr\$6,00

Cr\$3,00

Cr\$12,00

Para o café beneficiado, ter-se-ia que o custo, por saco, seria de $\frac{12,00}{40}=$ $=\mathrm{Cr} \$ 0,30$.

\section{3 - NUMERO DE INSTAIAAÇŌES FM FUNCIONAMENTO}

O Dr. Rudolf Isay informou que até setembro de 1950 o número de instalações em funcionamento era de 20 , sendo que a maioria está trabalhando com cafe beneficiado. A mais antiga instalação, em funcionamento, excetuando-se a sua própria, é a do sr. Reinaldo Massi, em Rolândia, a qual conta um funcionamento ininterrupto de um ano.

\section{4 - O PROBLEMA DA SEPARAÇÃO MAGNÉTICA DOS TORRÕES}

A fim de ter uma idéia sôbre o problema da separação dos torrões de terra roxa, fizemos algumas determinações visando a obtenção das dimensões mais frequentes nos torrões que acompanham o café beneficiado e o café da roça. 
E evidente que a percentagem de torrões no café é extremamente variável, pois depende da perfeição da colheita, o que não acontece com as dimensões relativas dos torrões, porquanto êstes dependem sobretudo do processo de preparo do café, e isto é pouco variável na mesma zona.

Com algumas amostras de café da roça retiradas na zona de Rolândia, Estado do Paraná, pudemos construir o gráfico representado na figura 6, que mostra a distribuição das frequências dos diâmetros dos torrōes. Ésse gráfico dá a distribuição da frequência dos torrões no café da roça, sem ter

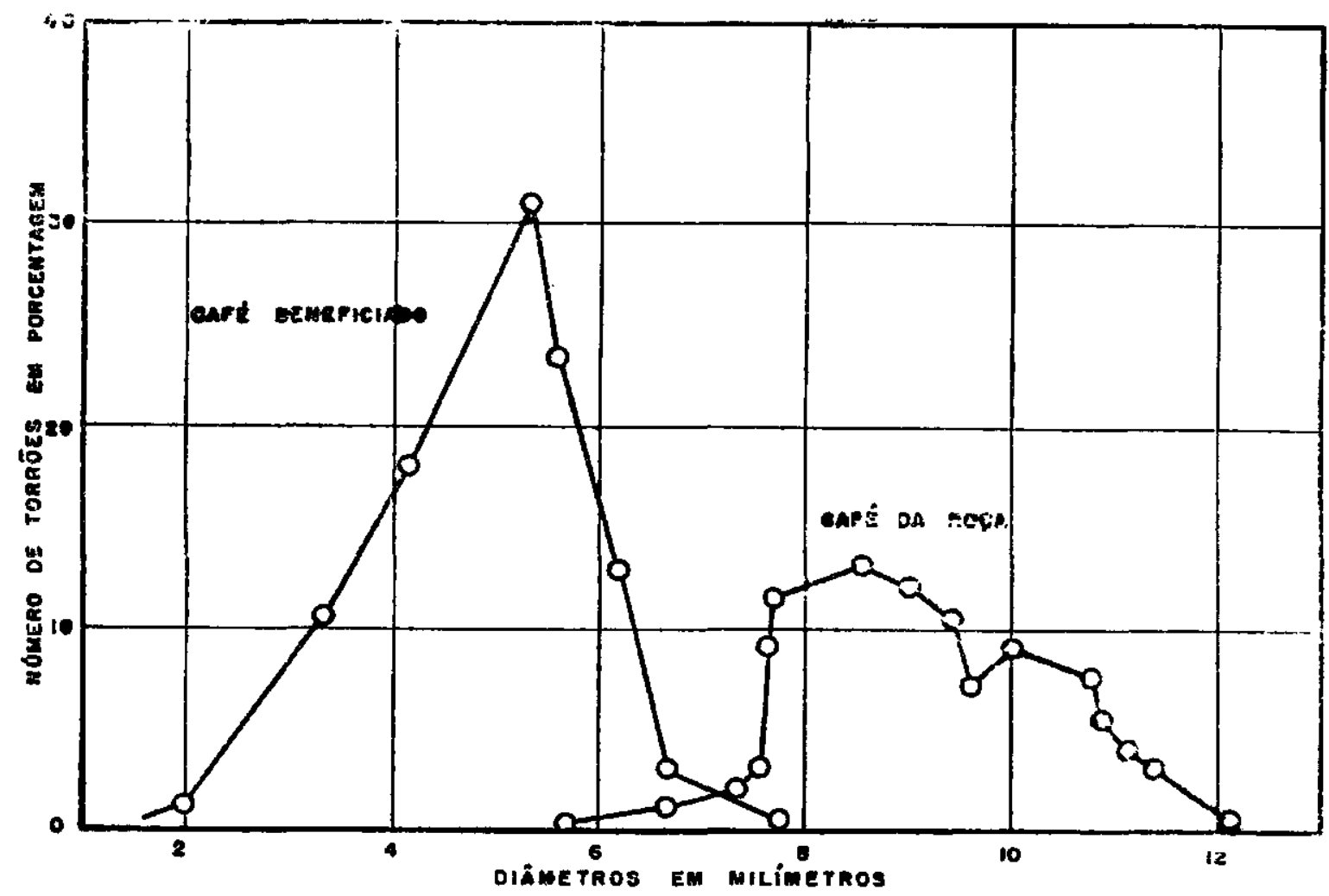

Figura 6.-Curvas de frequência do número de torrôes em percentagem, de acôrdo com o diâmetro das amostras de café beneficiado e de café da roça.

sofrido qualquer operação mecânica posterior à colheita, e por aí se vê que o diâmetro mais frequente é da ordem de 8,5 milímetros. A distribuição da frequência dos torrões no café beneficiado foi obtida com amostras separadas pelo catador magnético, referindo-se, portanto, aos torrōes separados pelo "Catador Dr. Isay". Aqui se verifica que o diâmetro mais frequente é da ordem de 5 milímetros.

Verificou-se que também no café beneficiado, não passado pelo separador magnético, a distribuição da frequência dos diâmetros dos torrões é pràticamente idêntica à do café beneficiado indicado na figura 6 . Isto demonstra que o café da roça carrega consigo a maior parte dos torrões com diâmetro variando em tôrno de 8,5 milímetros. Com o manuseio no terreiro ou no secador, e com a passagem pelo catador de pedras e, em seguida, pelo 
descascador, fica o café pràticamente livre dos torrões grandes, porque ou êstes foram separados, ou, com o trabalho, tiveram os seus diâmetros reduzidos.

Nestas condições, a função principal do catador magnético é a separação dos torrōes com menos de 7 milímetros de diâmetro, quando se trata de trabalhar com café beneficiado.

No caso de se trabalhar com café da roça, a função do catador magnético é mais difícil, pois êle deverá separar torrões com cêrca de 9 milímetros de diâmetro ou mais.

É recomendável o uso do catador de pedras ou do seletor para o café da roça, pois com estas máquinas os torrões grandes, de 9 milímetros para mais, são separados com bastante eficiência.

\section{1 - ALGUNS DADOS SÔBRE OS TORRÕES DE TERRA ROXA}

Vimos que o diâmetro mais frequente dos torrões, que são separados pelo catador magnético, é de cêrca de 5 milímetros. Diante disto podemos calcular o pêso do torrão, baseado no seu pêso específico real, médio.

Fizemos algumas determinações do pêso específico real e aparente, sendo que os resultados médios obtidos foram os seguintes:

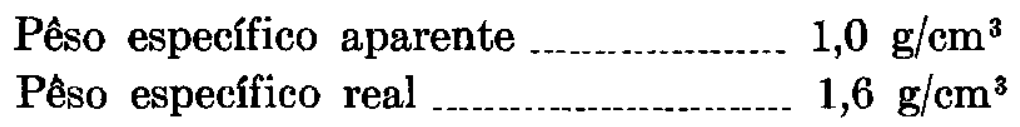

É evidente que êste dado varia com diversos fatôres, dentre êles a umidade ; porém, êstes números se referem às condições de torrões comumente encontrados junto com o café.

Baseado nestes números e admitindo-se o torrão como sendo de forma esférica, o pêso do de 5 milímetros de diâmetro é da ordem de : 0,1 grama. Vimos que a quantidade de magnetita contida na terra roxa chega, em alguns casos, até $8 \%$ ou mais. Admitindo-se, como têrmo médio, $4 \%$, tem-se que o pêso de magnetita contida no torrão é da ordem de $4 / 100 \times 0,1=0,004 \mathrm{~g}$.

Estas 4 miligramas de magnetita contidas no torrão de 5 milímetros de diâmetro são responsáveis pela fôrça de atração magnética ocasionada pelo ímã, e a esta fôrça se opõe principalmente a fôrça centrífuga a que fica sujeito o torrão, provocada pelo movimento de rotação do rôlo magnético.

\section{2 - AÇÃO DA FÔRÇA CENTRIFUGA}

Os torrões, ao caírem sôbre o rôlo magnético rotativo, ficam sujeitos à ação da fôrça centrífuga, além da do seu pêso. A resultante destas duas fôrças se opõe à fôrça de atração magnética.

Agindo a fôrça centrífuga com muito maior intensidade do que o pêso do torrão, podemos considerar que a resultante destas duas fôrças é pràticamente igual à fôrça centrifuga. 
Chamando $f c$ o vector fôrça centrifuga e $p$ o vector pêso, temos :

$$
\mathrm{fc}=\mathrm{k} \quad \mathrm{n}^{2} \mathrm{p},
$$

،em que

$$
\mathrm{k}=\frac{\pi^{2}}{900 \mathrm{~g}} \cong 0,0012
$$

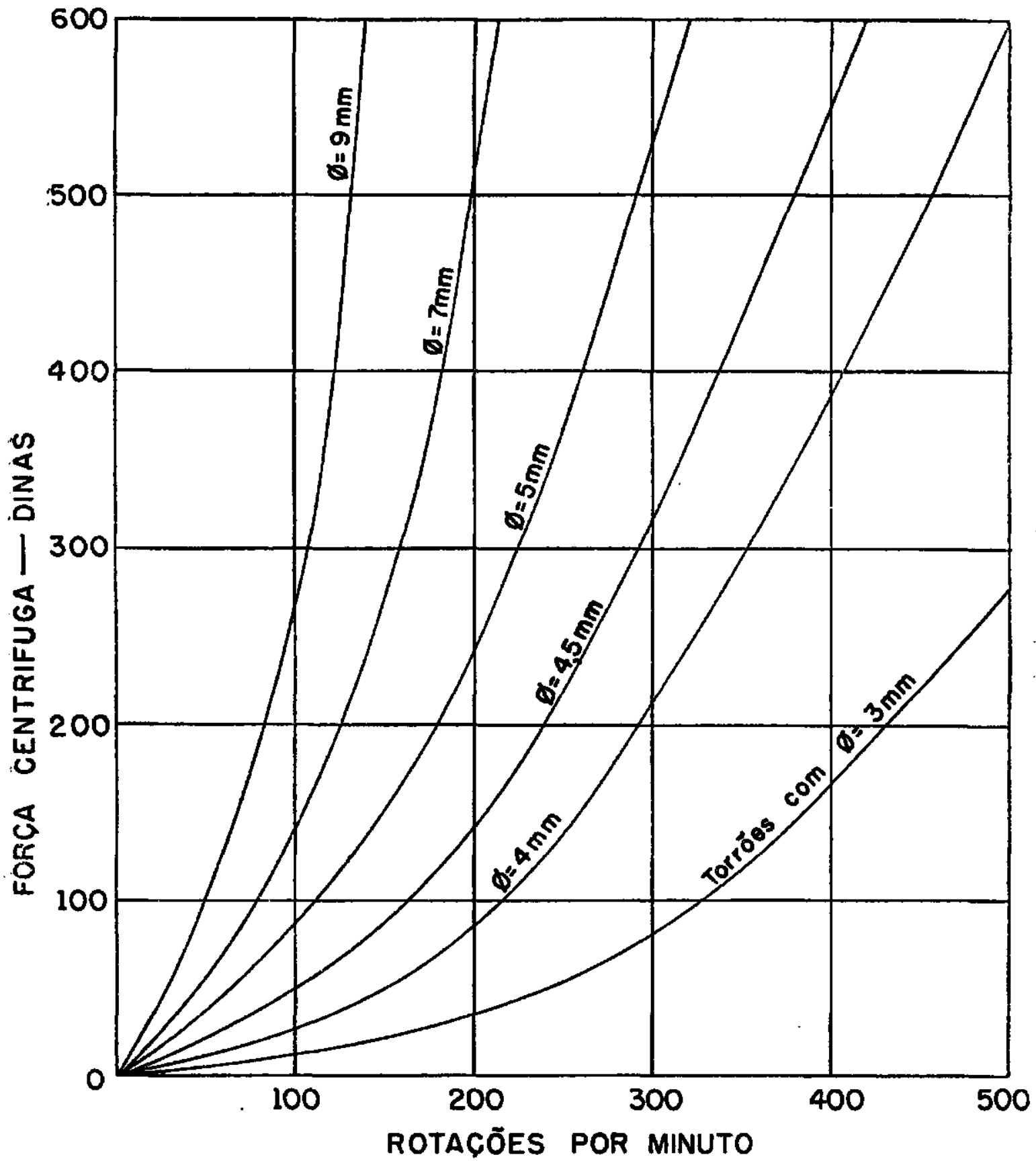

Frgura 7.-Curvas da fôręa centrífuga em função do número de rotações por minuto a que estão sujeitos os torrões de diferentes diâmetros no "Catador Dr. Isay".

$\mathbf{r}=$ raio médio do rôlo magnético

$\mathrm{n}=$ número de rotações por minuto do rôlo magnético

$\mathrm{g}=$ aceleração de gravidade 
Dêsse modo, para uma partícula de 5 milímetros de diâmetro, cujo pêso scja da ordem de $1 / 10$ de grama, teríamos, para valor de fe, o rôlo girando a 240 r.p.m. e tendo como raio médio 4,5 centímetros :

$$
\mathrm{f} c=31 \text { gramas ou } 305 \text { dinas, }
$$

que é muito maior do que o pêso do torrão.

$\widehat{\mathrm{E}}$, portanto, a fôrça centrífuga o elemento que se opõe à atração das partículas pelo rôlo magnético, e esta fôrça varia proporcionalmente ao pêso da partícula, o que equivale a dizer que varia proporcionalmente com o cubo do diâmetro da partícula e com o quadrado do número de rotações por minuto do rôlo magnético.

O gráfico da figura 7 nos dá a idéia da variação da fôrça centrífuga em função dos dois fatôres mencionados.

Verifica-se, portanto, que a eficiência da separação do "Catador Dr. Isay" depende, sobretudo, de se darem velocidades adequadas ao rôlo magnético, quando se trabalha com torrões de diâmetros diversos.

Assim, se admitirmos que o campo magnético do ímã é constante e igual a uma fôrça atrativa correspondente a 300 dinas ou 300 gauss $/ \mathrm{cm}$, verificamos que a separação sòmente seria possível para partículas inferiores a $4,5 \mathrm{~mm}$ de diâmetro num regime de rotação igual a 300 r.p.m. do rôlo magnético, ao passo que, para partículas menores do que $7 \mathrm{~mm}$ de diâmetro, o regime de rotação do rôlo poderia ser da ordem de 100 r.p.m.

Demais, outros fatôres intervêm na eficiência da separação, pois que o campo magnético do ímã, além de não ser uniforme à fôrça da atração, varia com a distância da partícula ao ímã.

\section{3 - OUTROS FATOTRES QUE AFETAM A EFICIENCIA DA SFIPARAÇÃO PELO CATADOR MAGNETICO}

Fvidentemente, sendo a fôrça de atração da partícula dependente da posição desta, em relação ao ímã no momento da sua queda sôbre o rôlo magnético, a cficiência da separação dependerá da probabilidade de a partícula cair num ponto mais favorável no campo magnético.

Esta probabilidade, naturalmente bastante difícil de se determinar, provàvelmente dependerá, entre outros fatôres, dos seguintes : quantidade de café trabalhado por unidade de tempo (da produção da máquina) ; velocidade do rôlo magnético; forma e dimensões das partículas e forma do entreferro.

A forma e as dimensões das partículas não podem ser alteradas arbitràriamente, pois é evidente que temos que trabalhar com as que se apresentam no café. Resta-nos estudar a influência que os outros fatôres já mencionados poderiam exercer na eficiência do separador magnético.

Parece-nos que, à medida que se aumenta a alimentação com o acúmulo de partículas que caem ao mesmo tempo sôbre o rôlo magnético, uma parte delas não pode cair no ponto mais favorável do campo magnético ; de outro lado, a maior velocidade do rôlo daria menos tempo para que uma 
dada partícula, embora caindo em posição desfavorável, se acomodasse num ponto de maior intensidade do campo. Evidentemente êstes pontos de vista podem ser, de certo modo, verificados experimentalmente, com ensaios cuidadosos e bem conduzidos.

E claro que a forma do entreferro constitui um dos principais fatôres para a eficiência da separação.

Para têrmos uma idéia da influência do entreferro, vamos delinear, em linhas gerais, o problema teórico da ação do campo magnético sôbre uma dada partícula contida nesse campo.

\section{4 - ESTUDO TEORICO}

A figura 8 representa uma partícula $\mathrm{P}$ entre os pólos do ímã os quais foram cortados por uma seç̧ão axial. Vamos admitir $\mathrm{Nn}$ e $\mathrm{Ss}$ as retas

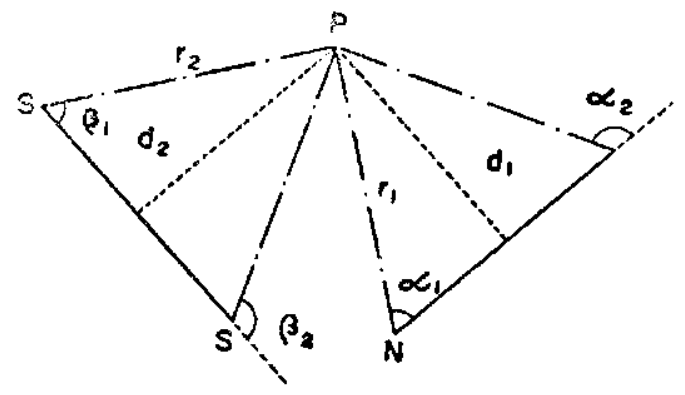

Figura 8.-Partícula $P$ entre os pólos do ímã, em corte axial.

representando os pólos norte e sul, respectivamente. As retas Nn e Ss não são nada mais do que a linha perimétrica da secção do entreferro, do "Catador Dr. Isay".

Sabe-se que a intensidade do campo magnético produzido pelos pólos Nn e Ss, no ponto $\mathrm{P}$, é dada por:

$$
\begin{aligned}
& \mathrm{H}_{\mathrm{t} 2}=\frac{1}{4 \pi \mu_{\mathrm{n}}} \int \frac{\mathrm{dm}}{\mathrm{r}_{1}^{2}} \\
& \mathrm{H}_{\mathrm{s}}=\frac{1}{4 \pi \mu_{0}} \int \frac{\mathrm{dm}}{\mathrm{r}_{2}^{2}}
\end{aligned}
$$

em que $\mu_{0}$ é a permeabilidade magnética do meio (constante no nosso caso) e $r_{1}$ e $r_{2}$ as distâncias de $\mathbf{P}$ a um ponto qualquer de $\mathrm{Nn}$ e Ss, respectivamente.

E fácil verificar que :

$$
\begin{aligned}
& \mathrm{r}_{1}=\mathrm{d}_{1} \operatorname{cosec} \alpha \\
& \mathrm{r}_{2}=\mathrm{d}_{2} \operatorname{cosec} \beta
\end{aligned}
$$


e, portanto, vamos ter :

$$
\begin{gathered}
H_{n}=\frac{m}{4 \pi \mu_{0}} \int_{\alpha_{1}}^{\alpha_{2} \frac{d}{d_{1}^{2}} \operatorname{sen}^{2} \alpha} \\
H_{s}=\frac{m}{4 \pi \mu_{0}} \int_{\epsilon_{1}}^{\epsilon_{2} \frac{d}{d_{2}^{2}} \operatorname{sen}^{2} \sigma}
\end{gathered}
$$

donde :

$$
\begin{gathered}
\mathrm{H}_{\mathrm{n}}=\frac{\mathrm{m}}{4 \pi \mu_{0} \mathrm{~d}_{1}^{2}}\left[\frac{\operatorname{sen} 2 \alpha_{1}-\operatorname{sen} 2 \alpha_{2}}{4}+\frac{\gamma_{1}}{2}\right] \\
\mathrm{H}_{\mathrm{s}}=\frac{\mathrm{m}}{4 \pi \mu_{0} \mathrm{~d}_{2}^{2}}\left[\frac{\operatorname{sen} 26_{1}-\operatorname{sen} 2 \delta_{2}}{4}+\frac{\gamma_{2}}{2}\right] \\
\gamma_{1}=\alpha_{2}-\alpha_{1} \quad \gamma_{2}=\delta_{2}-6_{1}
\end{gathered}
$$

$O$ valor da intensidade $\mathrm{H}$, do campo magnético, no ponto $\mathrm{P}$, será obtido pela resultante dos vectores $\mathrm{H}_{\mathrm{n}}$ e $\mathrm{H}_{\mathrm{s}}$.

Analisando ràpidamente estas fórmulas, verifica-se que a intensidade $H$ do campo depende, além das distâncias $d_{1}$ e $d_{2}$, do ponto considerado aos pólos do ímã e, o que é evidente, também dos ângulos, o que equivale a dizer que depende da forma do entreferro.

$\mathrm{O}$ caráter dêste trabalho não nos permite uma análise teórica rigorosa do problema; mas pode-se ver em linhas gerais a complexidade e importância desta questão.

É claro que o problema teórico aqui delineado não corresponde à realidade, pois que os pólos, aqui representados apenas pelas linhas $\mathrm{Nn}$ e Ss, na verdade são constituídos de superfícies cônicas. Todavia, o nosso intuito foi apenas chamar a atenção para esta questão.

É sabido, e as fórmulas expostas o demonstram, que a intensidade do campo magnético depende da massa magnética dos pólos do ímã e, em última análise, da energia magnética por unidade de pêso do ímã.

Tratando-se de ímã permanente, a energia magnética unitária depende, sobretudo, do ciclo de histerese do material.

\section{5 - MATERIAIS MAIS ADEQUADOS À CONSTRUÇÃO DÓS IMÃS PERMANEN'TES}

Modernamente têm sido empregados na construção de ímãs permanentes materiais de alto poder de remanescência e fôrça coersiva. Dentre êstes, destacam-se certas ligas de ferro, alumínio, níquel e cobalto, genèricamente denominadas alnico $(2,3$ e 4). Existem no comércio diversos tipcs de alnico, conhecidos com o nome de alnico seguido de números: 1 , $2,3,4,5$ e 6 . 
O alnico 5 ou 6 , liga cuja composição aproximada é de $51 \%$ de ferro, $8 \%$ de alumínio, $14 \%$ de níquel, $24 \%$ de cobalto e $3 \%$ de cobre, tem sido o mais empregado, dado o seu alto valor da energia magnética unitária.

Para se ter uma idéia do valor do alnico 5 como material para ímã permanente, reproduzimos na figura $9 \mathrm{um}$ gráfico apresentado por H. J. Goss (1), engenheiro pesquisador da General Electric Company.

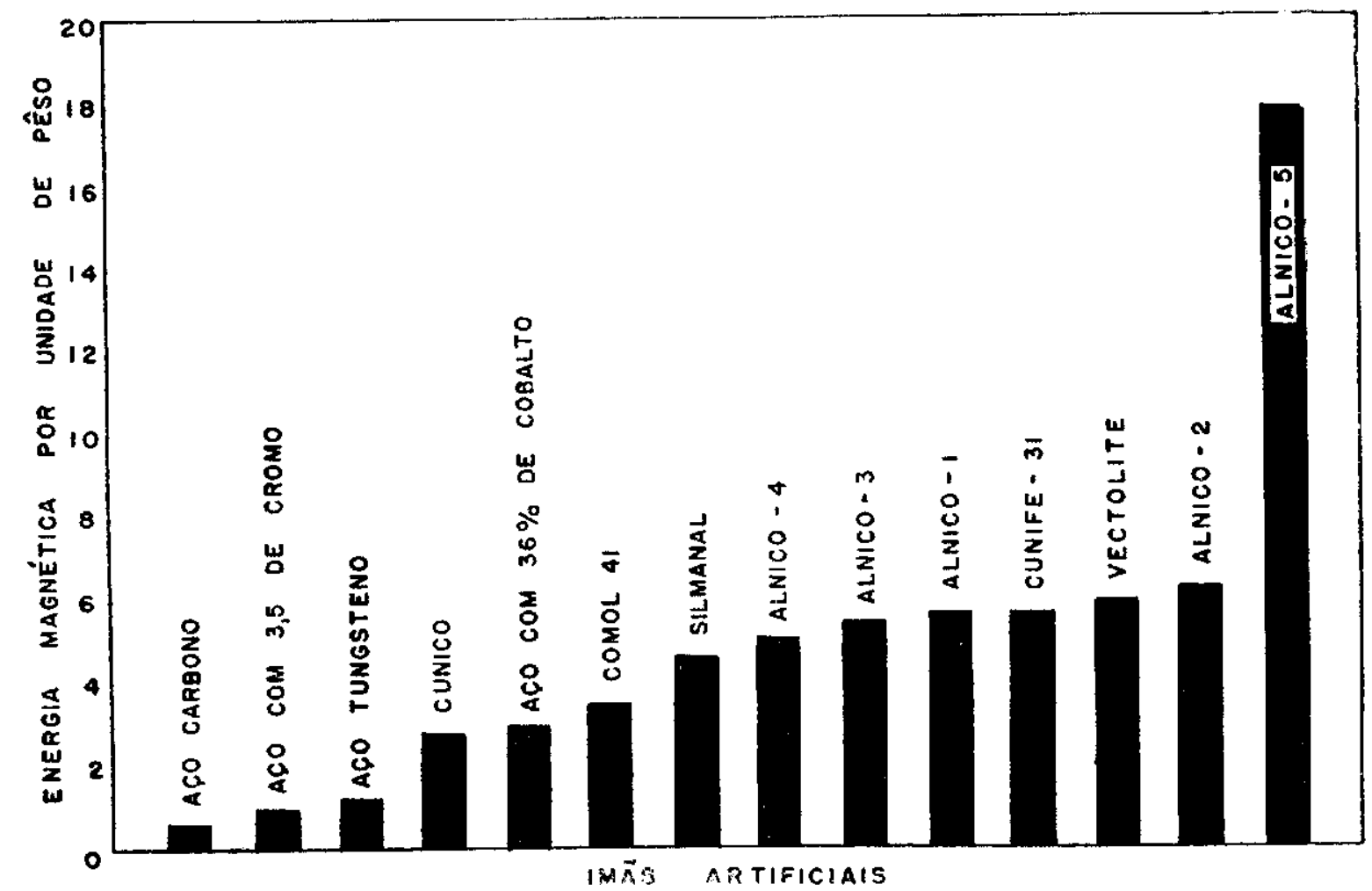

Figura 9.-Comparação da energia magnética por unidade de pêso de vários materiais empregados na construção de ímãs permanentes.

\section{5 - CONCLUSÕES}

Pelo que foi exposto, podemos concluir o seguinte:

1) A separação dos torrões de terra roxa que acompanham o café, nas zonas da média Sorocabana e norte do Paraná, constitui problema digno de ser estudado.

2) Até o presente momento, o único meio eficiente de separação tem sido o lavador. Nem o catador de pedras nem o seletor efetuam uma separação eficiente, a não ser para os torrões grandes.

3) É possível a separação dos torrões por meio dos separadores magnéticos, tanto os de eletroímãs como os de ímã permanente.

4) Os separadores de ímãs permanentes são mais práticos e, portanto, mais recomendáveis para as fazendas.

5) O "Catador Dr. Isay", de ímã permanente, efetua um serviço de separação eficiente para os torrões pcquenos, justamente aquêles que não são separados nem pelo catador de pedras, nem pelo scletor. 
6) O selctor, o catador de pedras e o "Catador Dr. Isay" se completam mùtuamente. É recomendável o emprêgo destas três máquinas, quando se quer uma separação perfeita.

7) No estudo teórico da separação pelo "Catador Dr. Isay", são importantes os seguintes fatôres: a) fôrça centrífuga a que está sujeito o torrão, dependente principalmente da velocidade do rôlo magnético e das dimensõcs dos torrões ; b) forma do entreferro ; c) caraterísticas do material empregado na construção do ímã permanente.

8) É recomendávcl o emprêgo, na construção do ímã pcrmanente, de ligas de alnico, principalmente alnico 5 ou 6 .

\section{SUMMARY}

In the regions of the so called "purple soils", in the State of São l'aulo and Northern Paraná, coffee harvested from the ground is attended by a number of foreign matter among which lumps of soils of varying sizes make up the bulk of it.

The separation of such lumps as attained by mechanical devices usually employed is always not satisfactory, the result being that remaining lumps will give a red colur to the coffee beans, thus lowering the grade.

Since the soil lumps have an appreciable amount of iron oxyde, mainly in the form of magnetite $\left(\mathrm{Fe}_{3} \mathrm{O}_{4}\right)$; there would appear that the use of electro-magnets or perm:1nent magnets of high power would give good results.

A new machine "catador Dr. Isay" having rotative permanent magnets thus appeared in the market and tests were officialy run to determine its perfomance. It was verificed that such machine performs a good job in the separation of small lumps, just the ones which are not efficiently separeted by other types of machines usually employed like "washers" (lavadores) "assorting machines" (seletores), and "stoners" (catadores de pedra).

A theoretical study of the new machine "catador Dr. Isay" was also perfomed, showing that the following factors are likely to have an important bearing on its performances : a) centrifugal force to which the lumps are subjected which is dependent upon the velocity of the magnetic rolls and the lumps effective size; b) shape of the "entreferro" ; c) characteristies of the materiil employed in the manufacture of the permanent magnet. In this respect it seems advisable to recommend the use of alnico alloys, mainly class 5 and 6.

\section{IITERATURA CITADA}

I. Goss, J. II. Ductile permanent magnets offer new design possibilities. Reprinted from Product Engineer, January, 1946.

2. Guillaumin, J. R. Les aimants permanents et le nickel. Revue du Nickel 16 : 79-90. 1950 .

3. Hicks, C. L. Nickel-Iron alloys for magnetic eircuits. Reprinted from electrical manufacturing, January, 1946.

4. Luerssen, G. V. Iron-Nickel alloys and their characteristics. Reprinted from Electrical Manufacturing, July, 1945.

5. Quittkat, G. et al. Em IIutte. Manual del Ingeniero, 4 : pág. 456, 2.a ed., Gusstavo Gili S.A., Barcelona, 1942.

6. Tosello, A. Ensaios sôbro o catador "Dr. Isay". Relatório da Seção de Café do Instituto Agronômico, 1950, (não publicado). 